\title{
جدلية التلقي واتجاهاتها في المسرح العربي
}

\section{أ.د. حمبيد صسابر

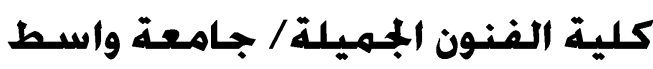 \\ مقدمة}

ظهرت في الساحة المسرحية العربية جماعات منظمة محاولة ايجاد صيغة مسرحية مغايرة تلبي حاجات الجمهور العربي ايماناً منها بانه ليس كل ما يقدم في الغرب صالح للجمهور العربي ـ لذا دعت الى نبذ الاشكال الغربية للمسرح ح والبحث عن صيغة جديدة للمسرح العربي، تتو افق مع طبيعة المشاهد العربي وخصوصيات ذوقه بعض اله ان لاحظت ان ان المشاهد العربي عزف عن منابعة كثير من العروض التي سارت على منهج المدارس المسرحية التي ظهرت في الغرب لكونها فصلت لمشـاهد

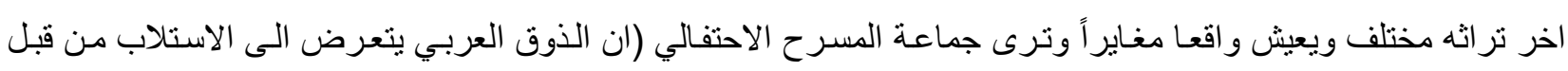

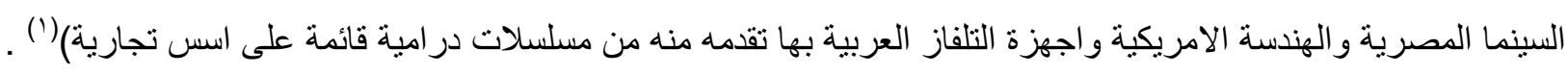

\section{اـ الامتفالبة : الاسلمب والتعامل هع المتاقي}

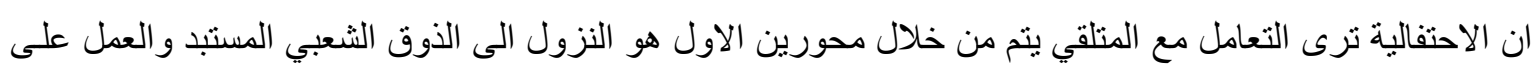

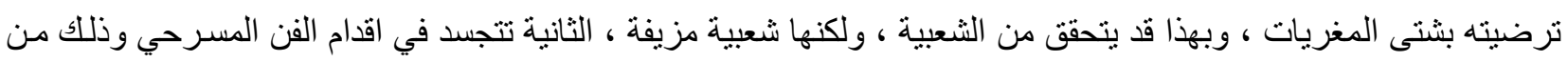

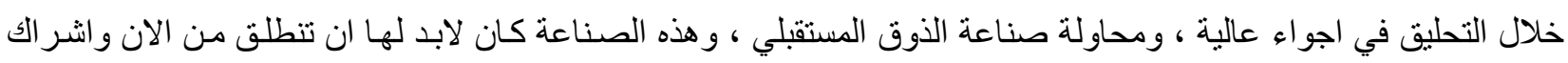

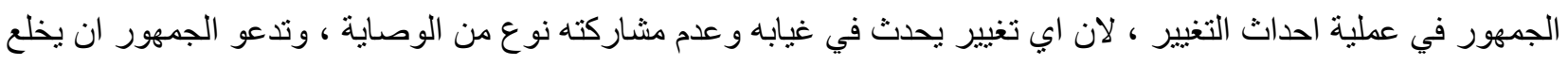

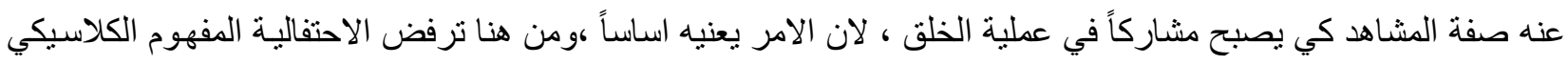

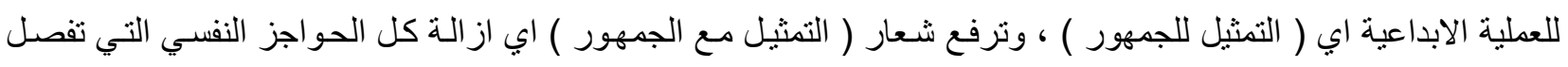
عادة بين العرض و الجمهور .

ويشيرون الى تقديم العرض المسرحي دون اظلام القاعة ، ودون ان يختفي المثلون لكي يرتدوا ملابس الثخصيات

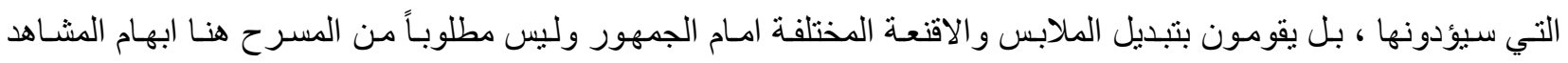

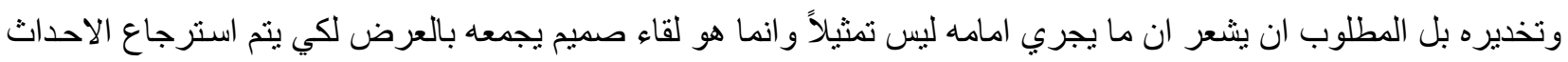

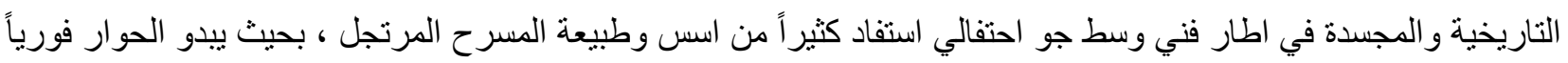

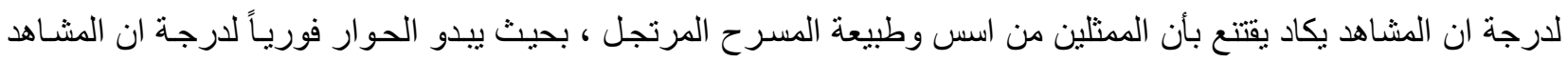
يكاد يقتنع بان الممثلين غير متقيدين بنص مكتوب ، وفي هذا الصدد يتحدث برشيد فائلاً :( النص الاحتفالي ليس شيئا جامداً ومغلقاً و انما هو مجرد تخطيط يعطي فرصة للارتجال بين الجمهور و التحاول معهم وذلك حتى يتحقق للفعل المسرحي انيته

وحيوته - و انتسابه الى اللحظة والناس وقضاياهم الحيوية ، لان الاساس في اللقاء ليس هو النص و وانما هو الحفل ) (؟) . وتساءل الاحتفالية في بيناتها الفكري الثاني كيف نجعل الجمهور متحركاً عوضـاً على ان يبقى سـاكناً كيف نجعله ،

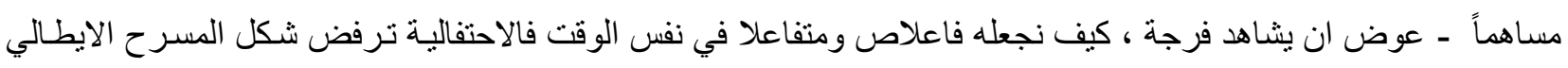

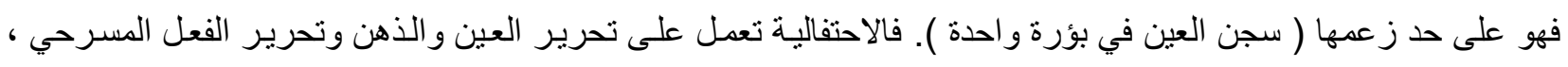

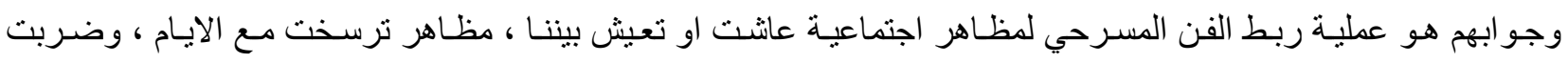

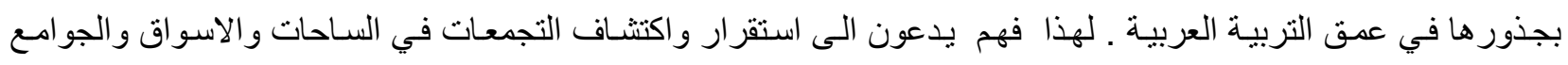

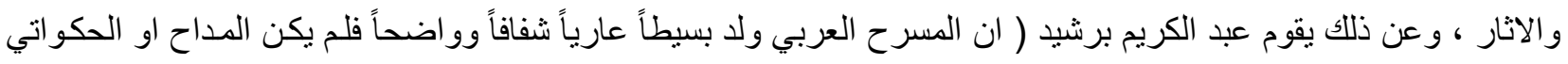
يحتاج الى ستارة ، لم يكن يتوسل بالاقناع بالملابس ، و الدكيور ، و المكياج ، ولم يكن يعتمد الا على مو هبته في الحكي و التقليد 
، و على عصاه السحرية لأنها تمتلئ ان تكون اي شيء ) (ّ). لان العمل الابداعي بالنسبة لجماعة المسرح الاحتفالي ضمير

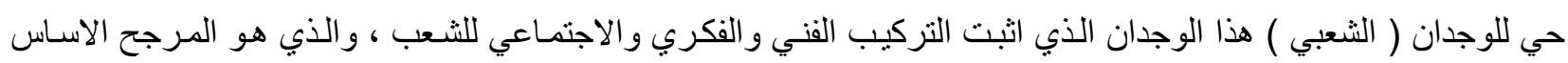
لهذلا الابداع .

ان الاحتفالية تقوم على المشاركة الوجدانية التلقائية فيصير المسرح كرنفالاً ، والغاية من هذِِ المشاركة هو البحث عن

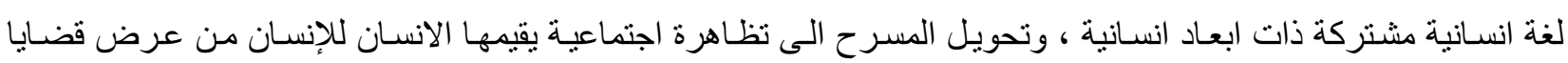

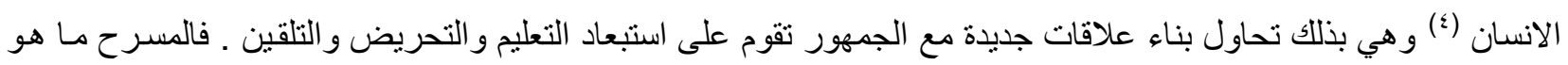
الا مؤتمر شعبي .

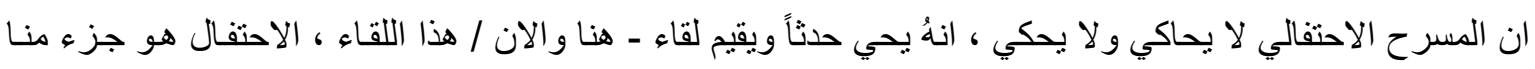

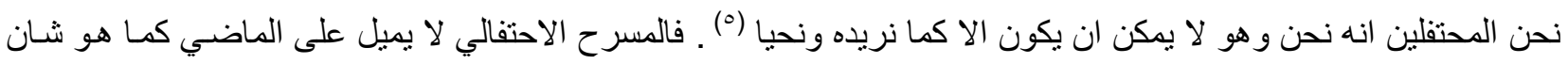

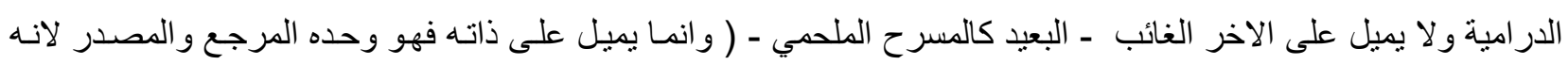

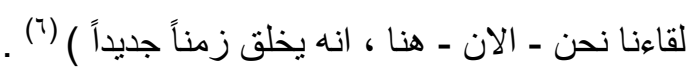

ان استلهام التراث من قبل ( الطيب الصديقي ) محتوى هدفه الاسـاس الاقتراب الحميم من المتلقي ، و الملاحظ في

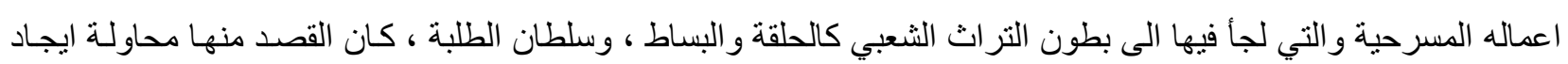

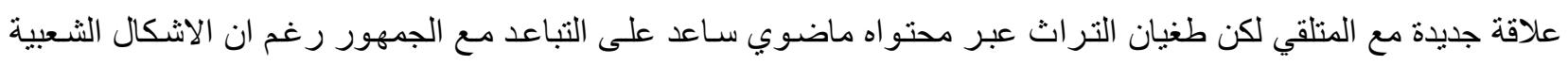

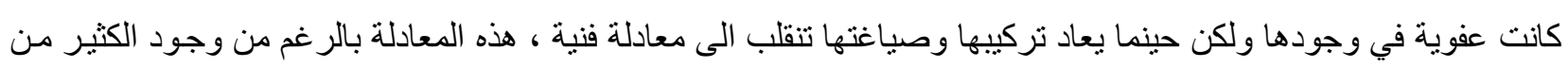

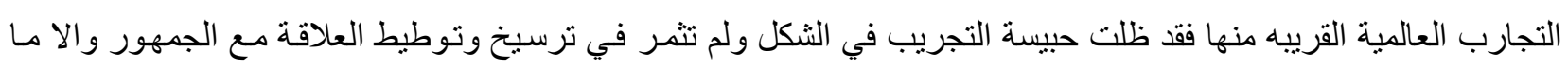

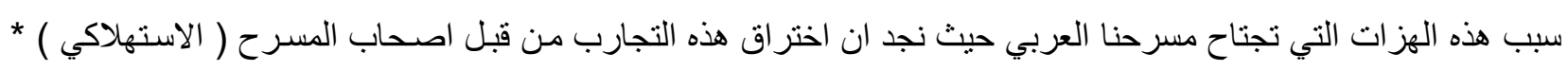

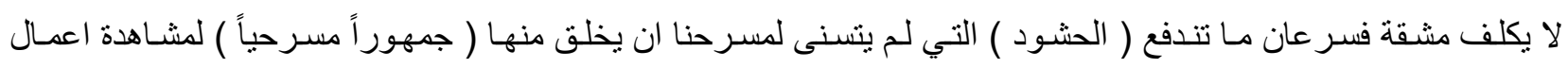

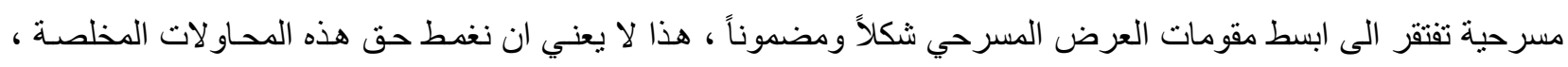

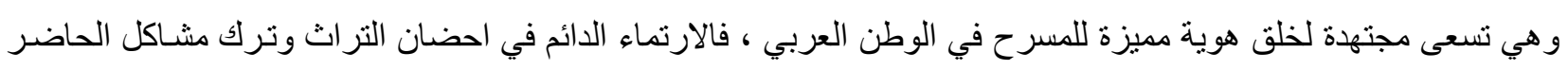

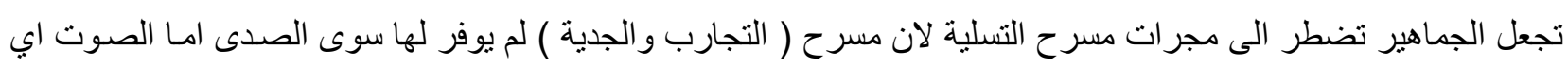

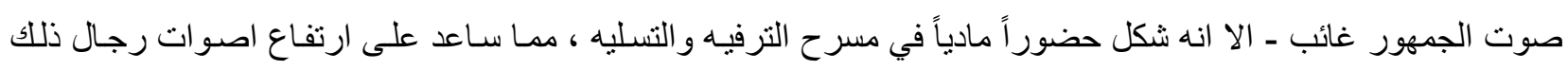

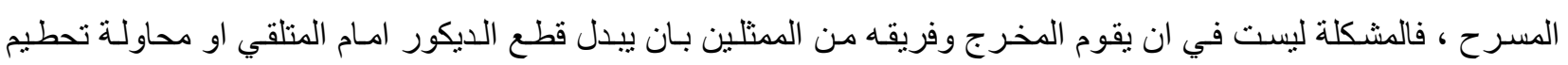

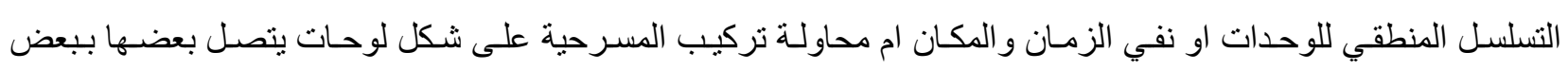
و الابتعاد كلياً عن كل ابهام مسرحي فلا ستارة و الممثلون يدخلون امام اعين الجمهور ويرتدون الملابس امـامهر ، و وانمـا تكمن

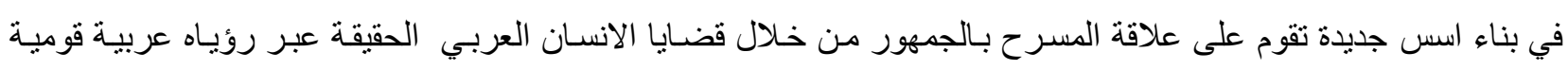

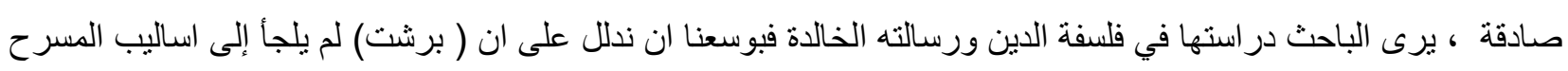

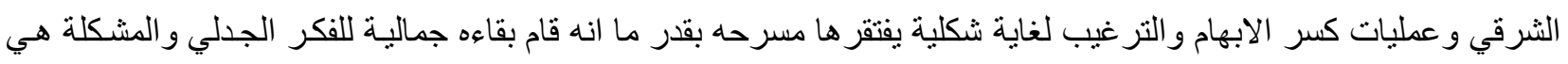

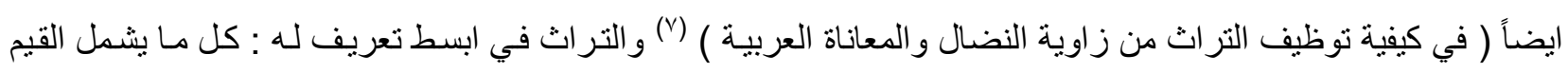

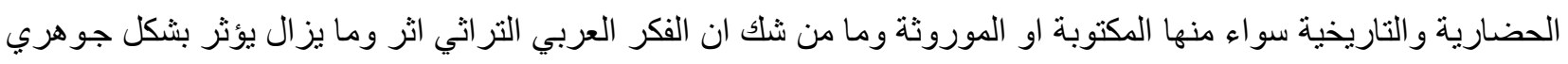

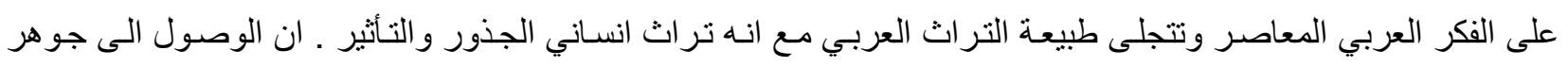

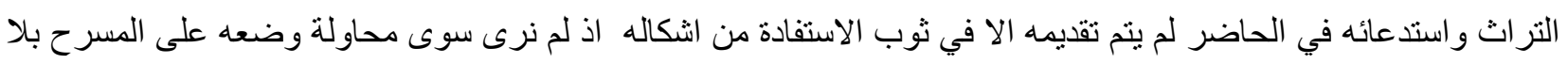
محتوى داخلي ذاتي . 


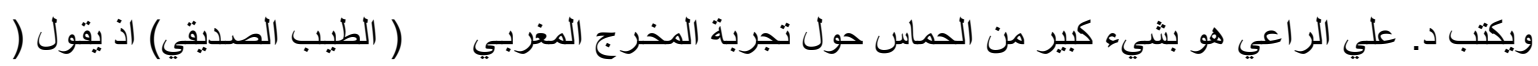

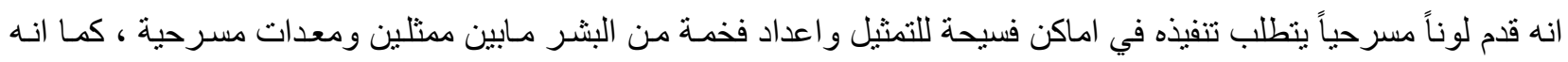

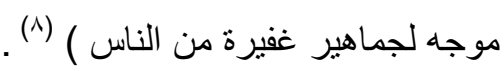
و د. علي الراعي كان يتحدث عن عرض مقامات بديع الزمان وتجربـة ديوان ( سيد عبد الرحمن المجذوب ) وهذه

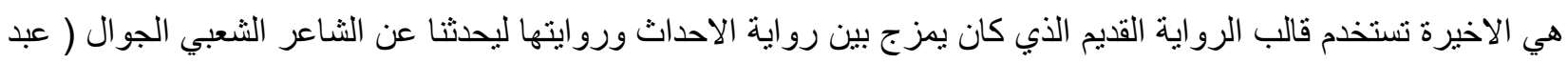

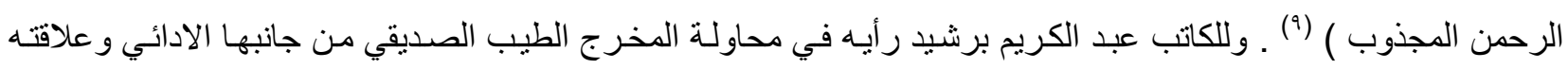

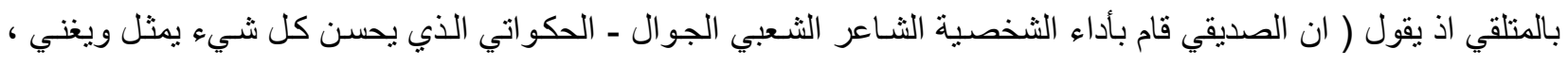

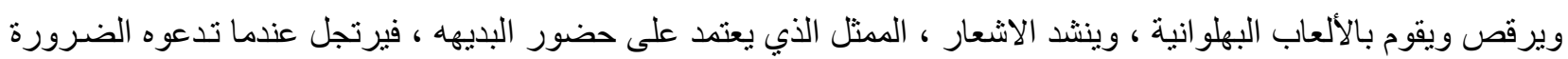
ويحس بالجمهور ويتفاعل معهه وتكون له عين ثالثة مركزة عليه ) (· (') .

\section{r. جماعة مسرة المكم|تي الابنانبة ومفهومها لاعلاقة مع المتلقي :}

ولدت هذه الجماعة من منطلق رفض المسرح السائد في لبنـان وسبب رفض مسرح الحكواتي ـ لما هو سـائد من

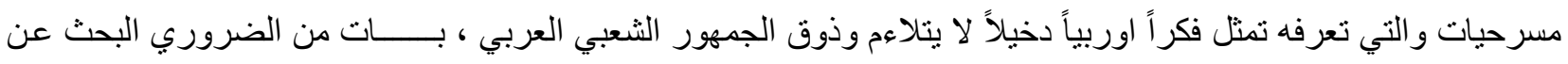

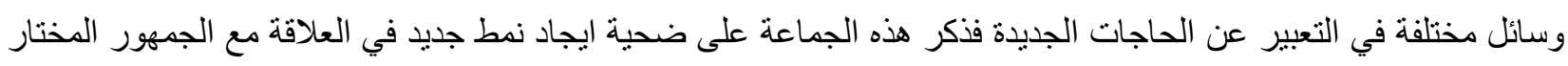
من الفئات الثعبية وهذا النط الجديد هو بالتحديد هو تحويل رؤية المشاهدين من رؤية سكونيه الى رؤية فاعلة تتيح لهم امكانية

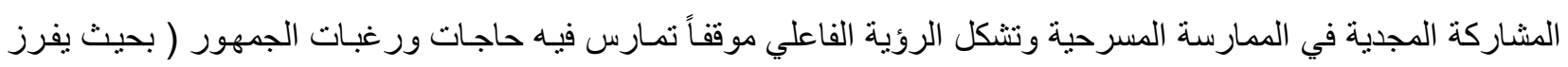

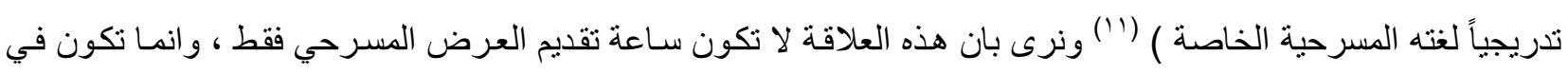

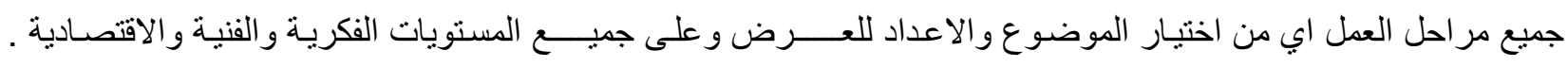

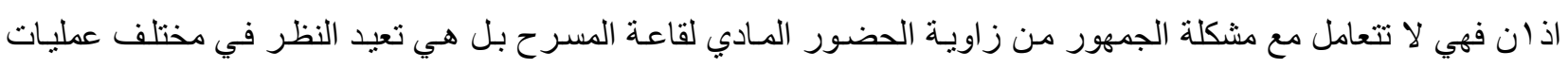
الانتاج و أساليب العمل ، اذ ان الفرقة انطلقت من اسس تشكل مفهوما لمديات العلاقة مع المتلقي.

فالفعل الجماعي لا يعني مجرد تجميع الخبرات و المو اهب ودمجها في قالب و احد فهي تؤكد على تجانس اعضـاء

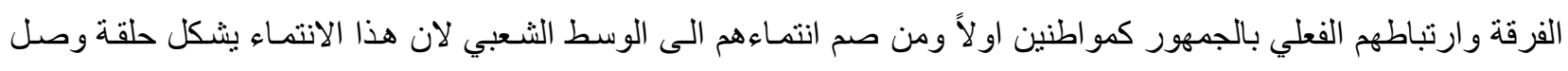

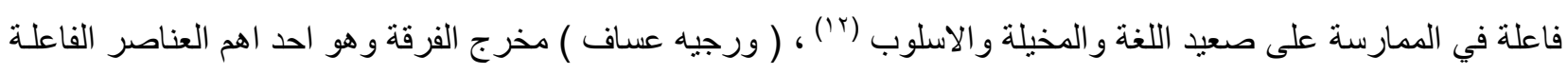

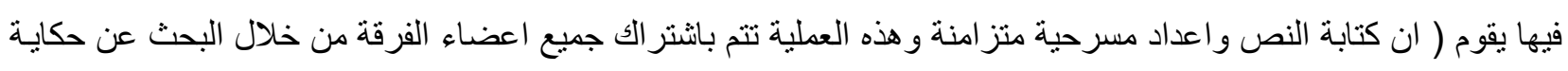

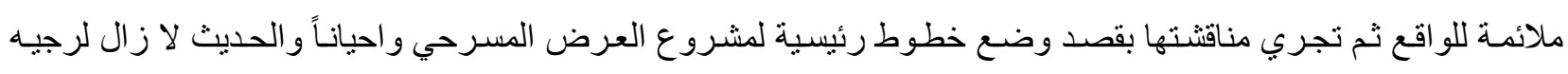
عساف ، و اثناء اعداد العرض تقوم بزيادة الناس وتجعل تفاصيل او مشاهد من المسرحية تتفاعل مع الجمهور حتى تسـاهم في ولي لئي

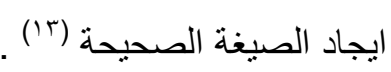

فالمثاركة هنا و العلاقة مع المتلقي هي علاقة دائمة وليست فقط اثناء العروض ويرى الباحث انهم يحاولون الاقتراب

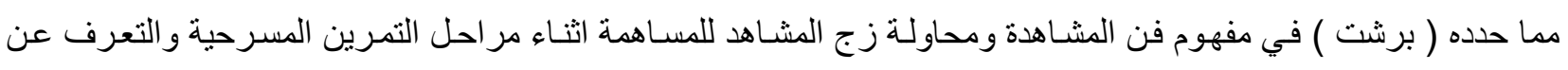

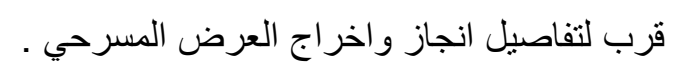

ان ( روجيه عساف ) يرفض تسمية مسرحنا ( بالمسرح العربي ) فهو يفضل ان يذكر ( الناطق باللغـة العربيـة ) ،

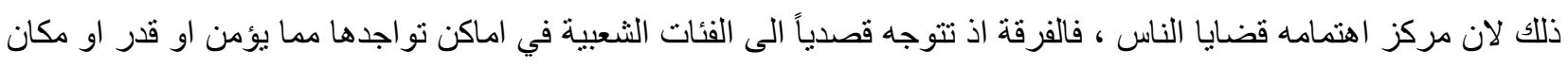

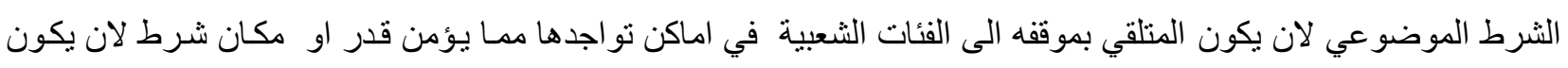

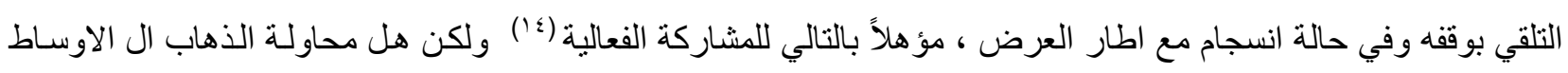


الثعبية يحقق مشاهدة الجمهور وخاصة اذا ما عرفنا ان هذه الفرقة تتحاز مذهبياً الى دون فئة اخرى محاولة تأطير صياغتها

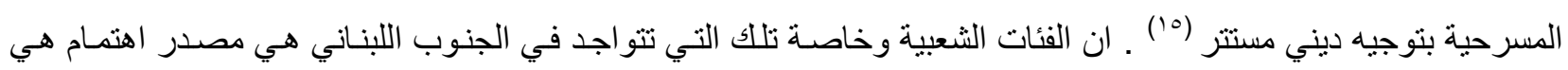

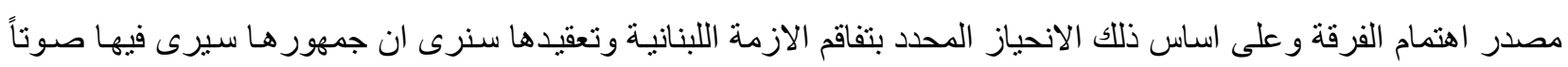

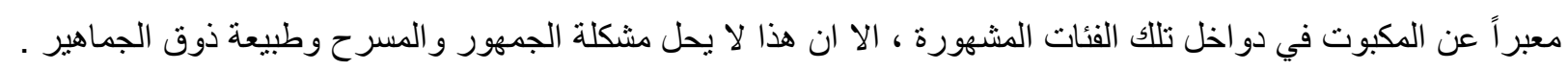
وتلجأ الفرقة في محاولتها للالتحام بالمتلقي الى استخدام الفنون الثـعبية ومنها الحكواتي ومنه جاءت تسمية الفرقة . فالحكو اتي بعلاقته المبانرة مع الجمهور ، بروي ويجسد المشاهد بواسطة ادوات بسيطة ومكثوفة ، ينطلق مسرح الحكواتي

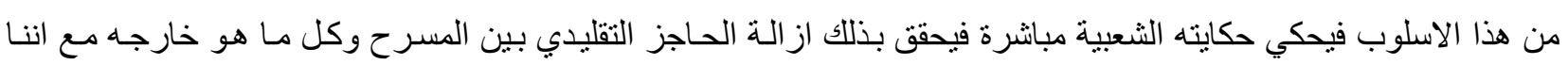

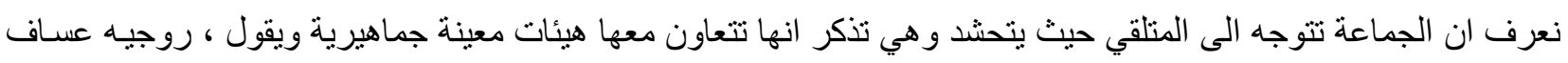

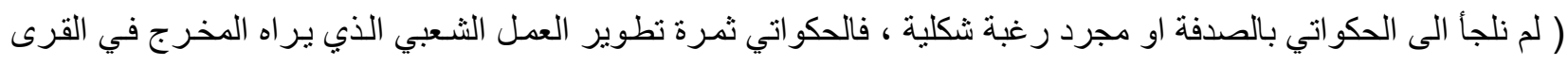

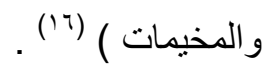
والحكايات الثتعبية التي يركز عليها المخرج ( روجيه عساف ) من شـأنها ان تربط المتلقي بذاكرتهـه وتبرز الرموز

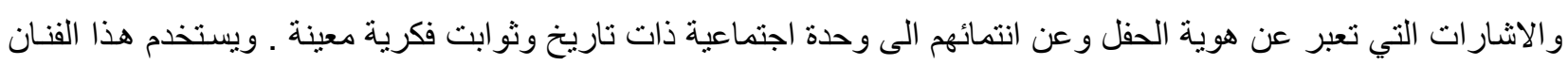
و الذي هو المنشد او الراوي او الحكواتي والذي يروي ويرقص ولائ يخفي بشخصية وراء احداث الحكاية او يتقنع ( فهو المثنل

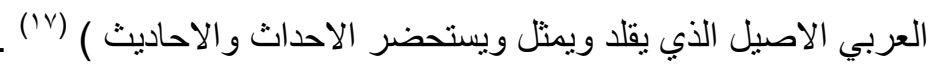

وفي الوقت نفسه يعبر عن شعوره ويحتفل مع الناس مستخدماً اساليب فنية بسيطة ، صورته ، وجهه ، عصـا ، كرسيا

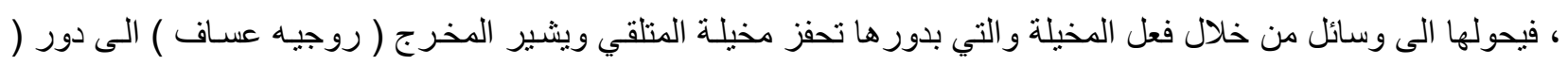

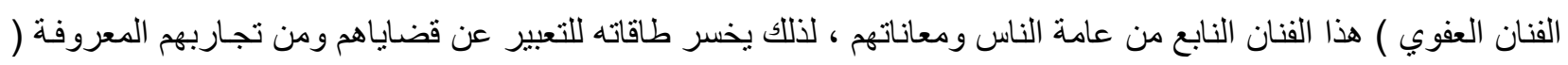

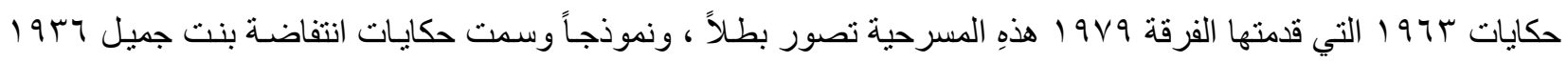

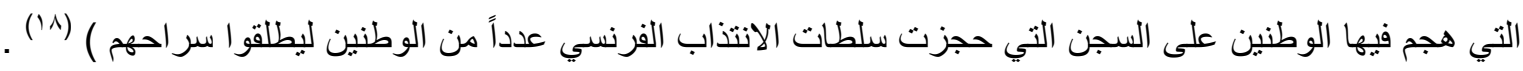
ومنهال العمل ، و الذي نـال شهرة مـن خلال مهرجان دمشق المسرحي يرى الباحث ان نهج هذه الجماعـة الشعبي

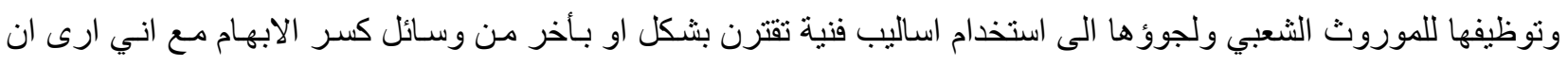

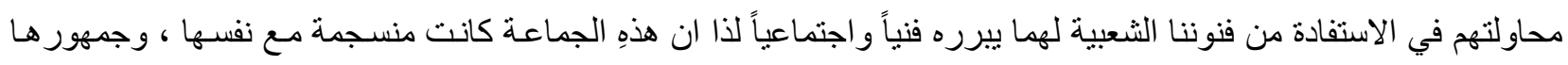

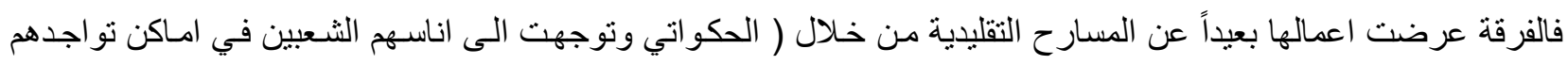

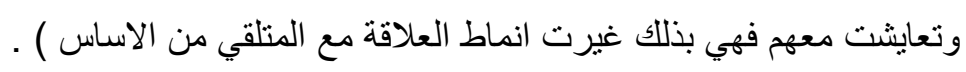

\section{1 ( ملاقة انسانية . \\ r. علاقة طبقية / شعبية / انتاجية . r. ملاقة فنية .}

فالمغزى الحقيقي لعرض حكايات حسو ا التاريخي هي محاولة لطرح الوقائع القديمة وربطها بو اقع الانسـان العربي

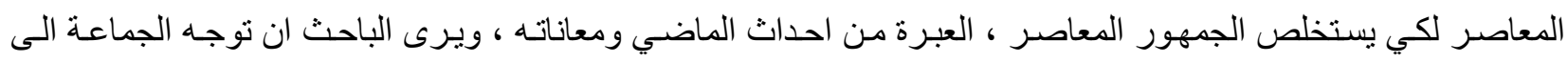
الجهور حيث يتو اجد لم يكن بدافع التخلص من ( مسرح العلبة الايطالية ) ولم يكن ذللك بسبب حاجة مادية ـ و انما كان الهدف

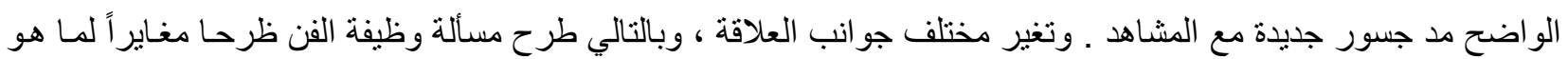
سائد ـ ومناقثة طبيعة الجمهور ازاء عروض معينة لا بد لنا على ذائقة الجمهور العربي ـ فطبيعة الجمهور العربي مرنبطة 
اشد الارتبـاط بازٔمة ( المجتمع العربي الحديث ، و لأنه كما لاحضنـا ان الازمـة ( اي ازمـة الجمهور في المسرح ) لم تأخذ

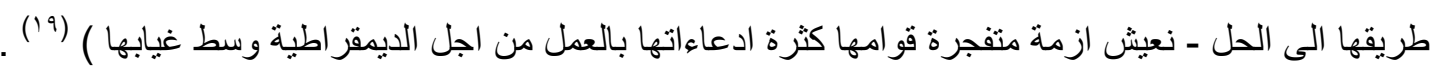
ويستمر د. ابر اهيم في طرح ملاحظاته حول عزلة الجهور عن المسرح رغم مـا استمدته التجارب المسرحية في

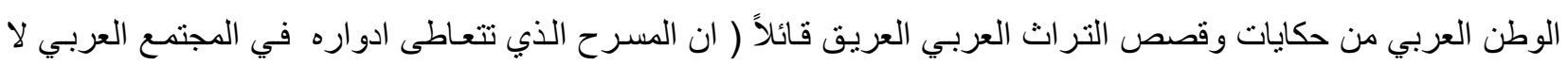

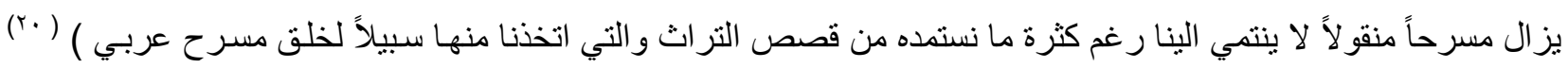

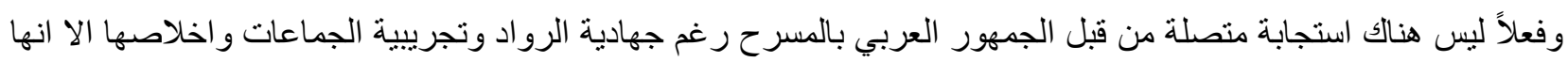
ضلت تدور في مختبرات وتجارب المسرح العالمي فمن السهل ان ترى تقارب او اوجه تشابه بين الكثير من الاتجاهـات الفنية المعاصرة في المسرح كالمسرح الحي او الخبز و الدمى او مسرح الثمس او مسرح ( لاكومونه ) الى المسرح الثعبي و الفرقة

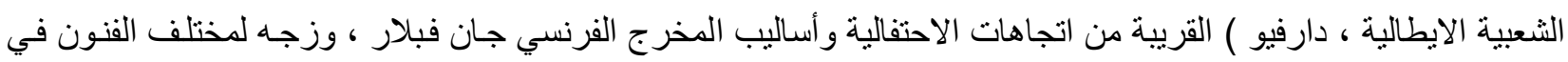

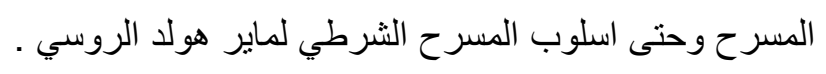

يرى الباحث ان الجماعات المسرحية العربية تضل رغم اجتهادها تدور في فلك التنظير المجرد اكثر من محاولات

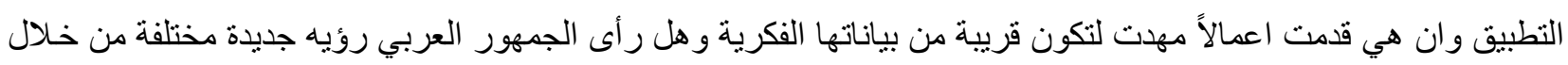

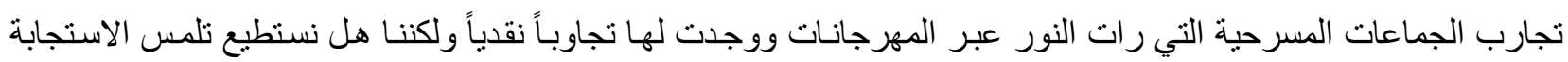

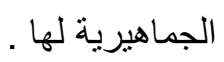

اي هل حدث تو اصل حضاري بوظيفة المسرح ـ ان هذه الجماعات المسرحية استمدت مصادر ها الفنية من الموروث

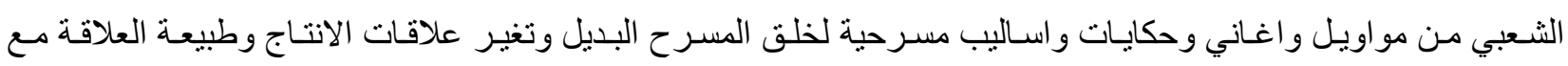
الجمهور منطلقين من اهمية المسر ح الثعبي لا الرسمي و هذا المسرح الذي يرتبط ظهوره دائما بحاجة الجماعة لتأكيد كيانها ،

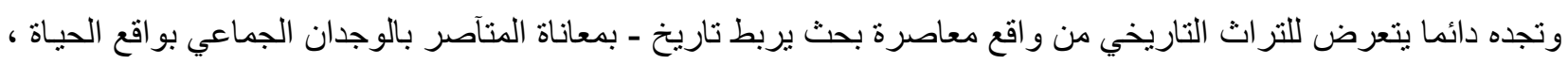

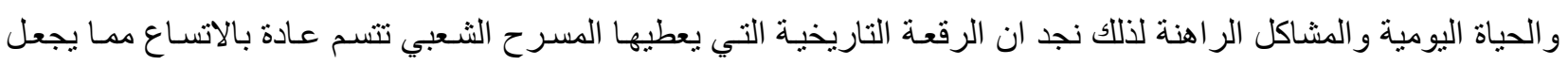

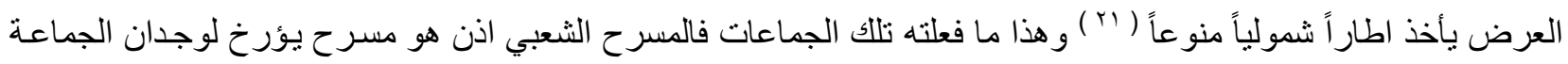

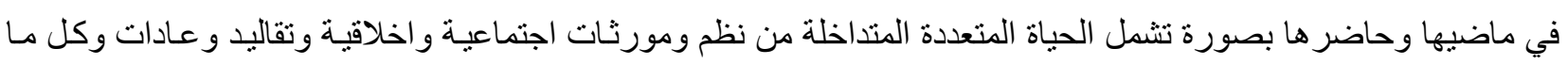

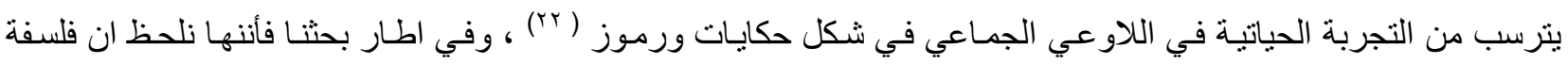

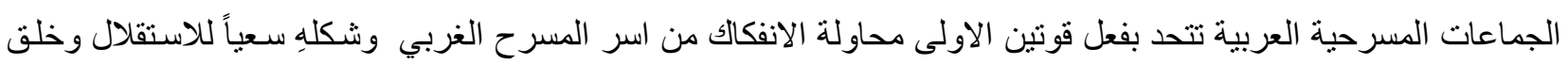

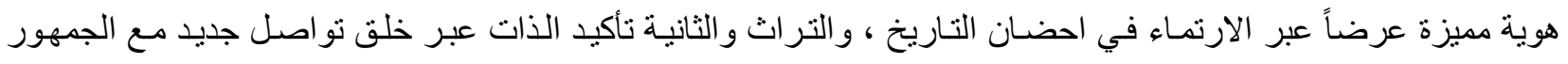

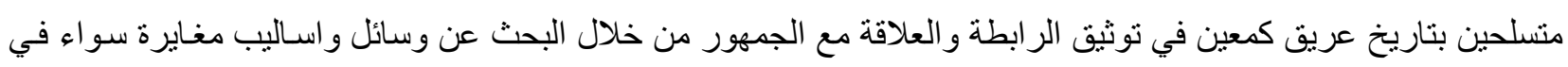
هندسة المكان واسلوب الاداء و علاقات الانتاج .

و اذا كانت هذه المحاو لات قد وققت عند نوظيف التراث و استلهام بعض الياته الثعبية من اجل تحقيق الصيغة الجديدة

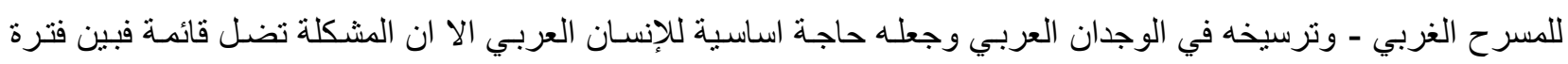

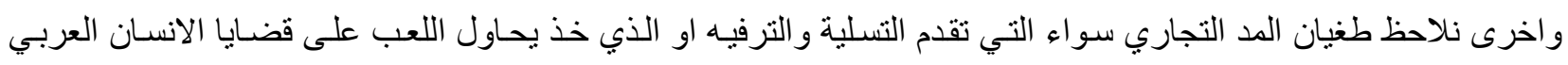
مستتر اً بالمسرح النقدي او التنفسي ، والامر الجدير بالذكر والذي تؤكد عليه ( تلكم الجماعات في تجاربها المسرحية هو

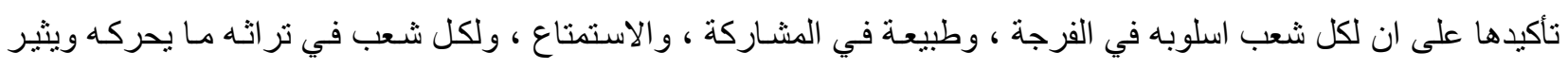

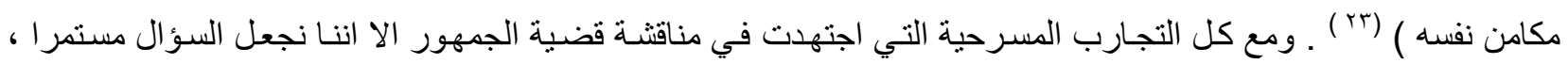
و على لسان المخرج ( سعد اردش ) قائلا ( لماذا لم يحقق المسرح العربي وجوداً يتناسب مع كيان الامـة العربيـة ؟ ولمـاذا لم 
تصبح الجماهير العربية قوة ضاغطة تسعى من اجل مسرحها ؟ ويضع جوابه بصيغة الاحتمال اذ يذكر ( ان المسرح العربي

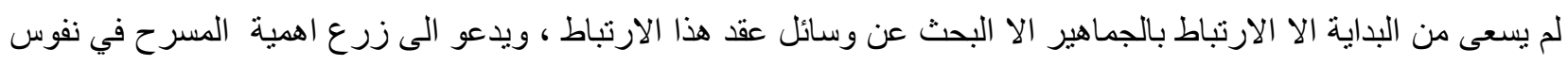

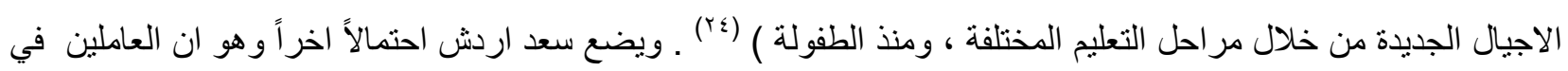

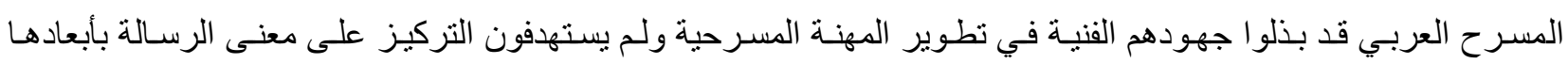

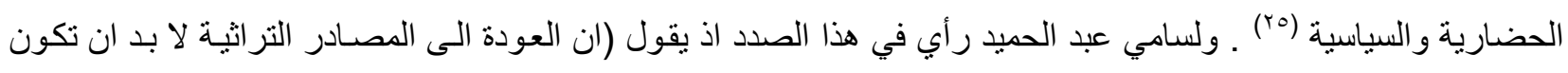

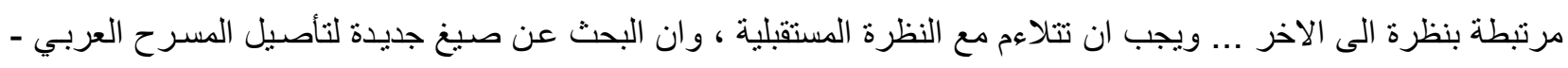

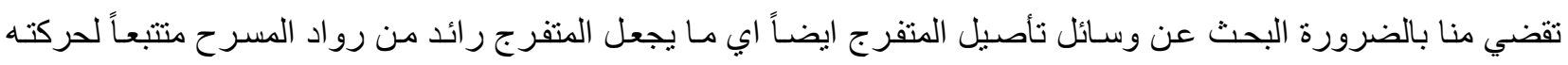

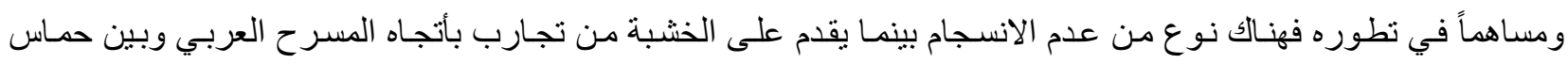
(الناس)(

ان تللك الجماعات لم تسنطع ان تبلور وتخلق جمهوراً فهي ظلت تدور باحثة عن وسائل للتو اصل و الحذب وسر عان ما

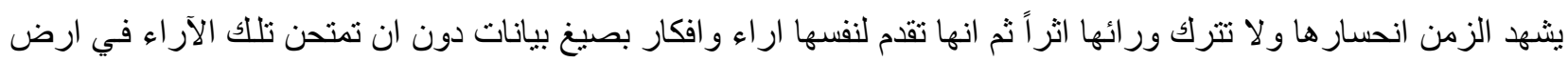
الو اقع رغم ان هذه الجماعات تخلط بين عدة اتجاهات مسرحية شهدها المسرح العربي جر اء ظروف لهرف مـا بعد الحرب الكونية

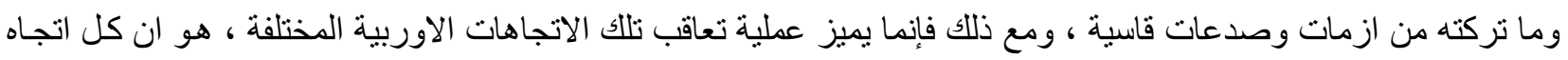

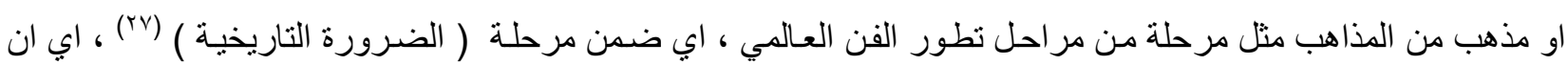

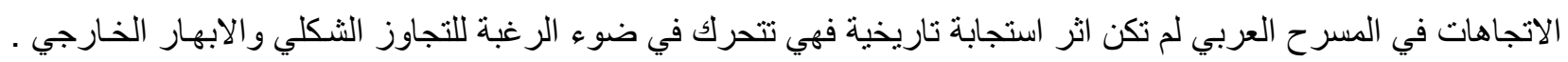

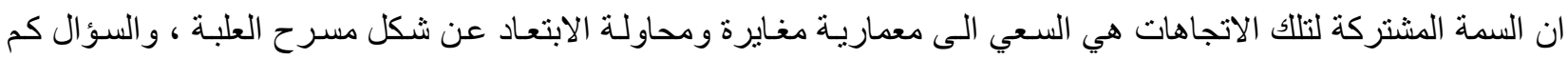

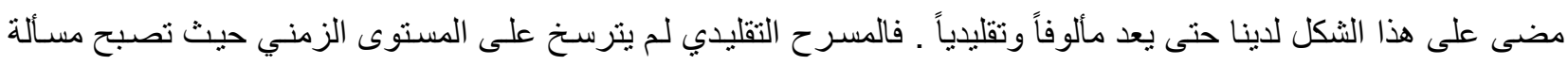

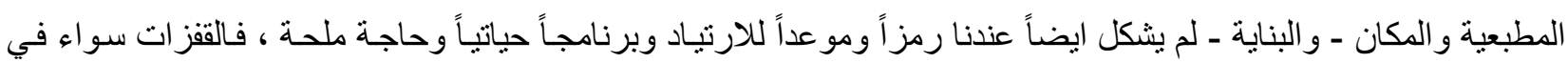

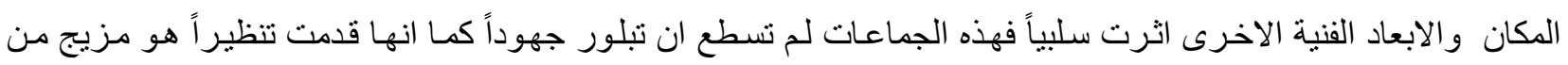

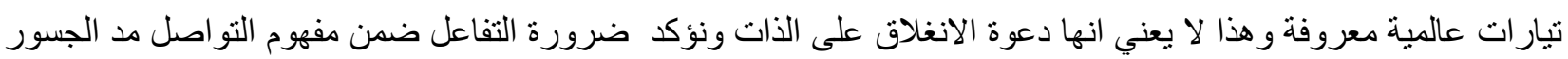
مع الاخرين في ظل خصوصيتنا القومبة .

الهوامشى والمادر

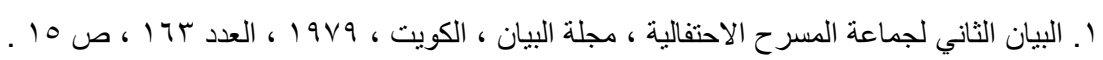

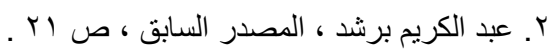

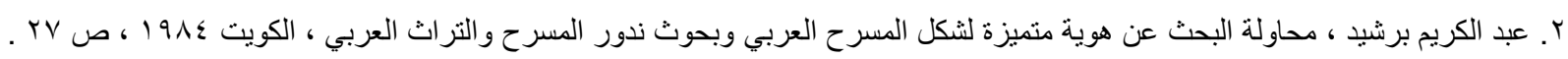

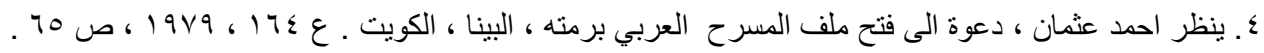

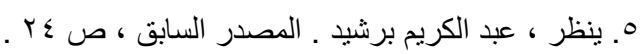

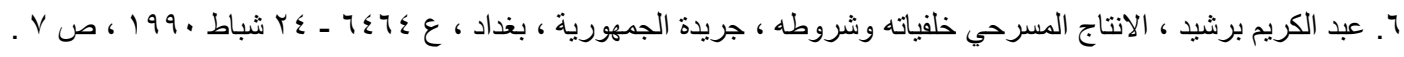

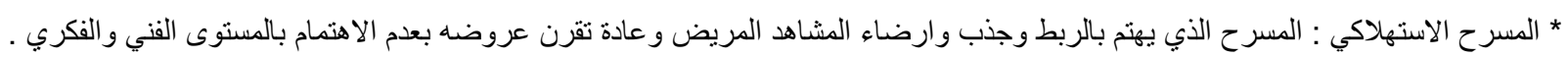

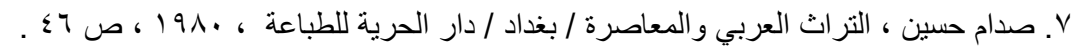

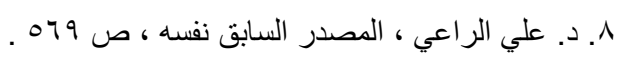

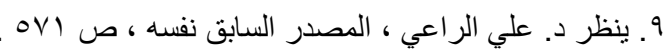

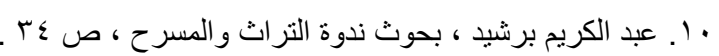

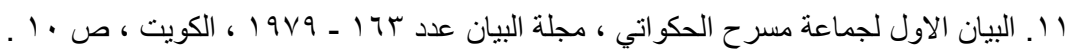

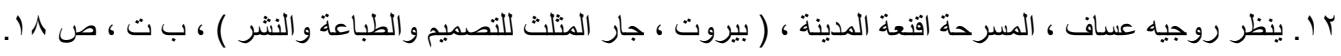

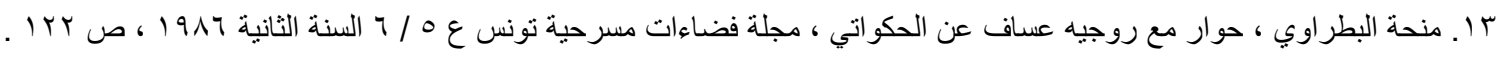


ع (. ينظر البيان الاول لجماعة المسرح الحكواتي ، المصدر السابق ، ص 11)

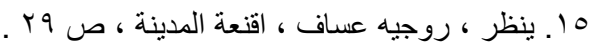

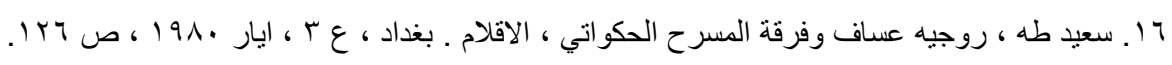

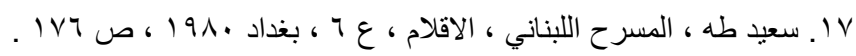

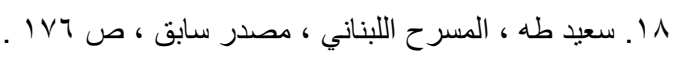

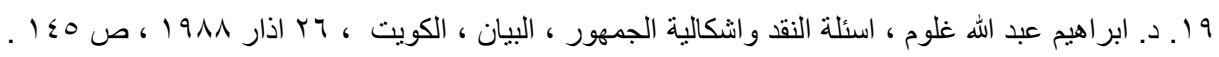

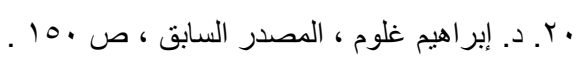

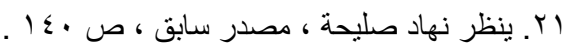

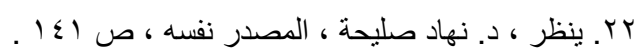

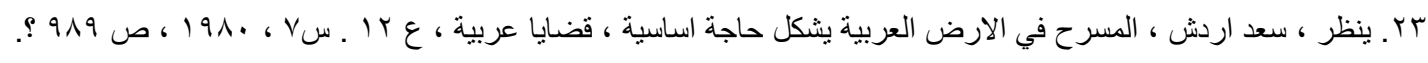

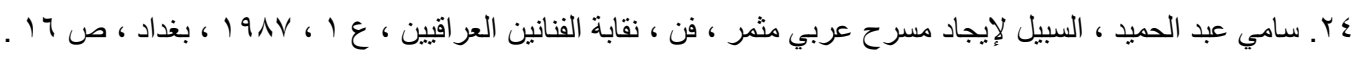

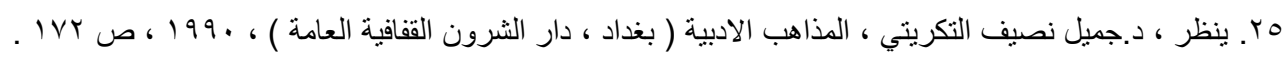

